\title{
Distinct roles for cysteine cathepsin genes in multistage tumorigenesis
}

\author{
Vasilena Gocheva, ${ }^{1,3}$ Wei Zeng, ${ }^{1}$ Danxia Ke, ${ }^{1}$ David Klimstra, ${ }^{2}$ Thomas Reinheckel, ${ }^{4}$ \\ Christoph Peters, ${ }^{4}$ Douglas Hanahan, ${ }^{5,7}$ and Johanna A. Joyce ${ }^{1,5,6}$ \\ ${ }^{1}$ Cancer Biology and Genetics Program, ${ }^{2}$ Department of Pathology, Memorial Sloan Kettering Cancer Center, New York, \\ New York 10021, USA; ${ }^{3}$ Weill Graduate School of Medical Sciences of Cornell University, New York, New York 10021, \\ USA; ${ }^{4}$ Institute for Molecular Medicine and Cell Research, Albert-Ludwigs-University Freiburg, Freiburg D-79104, Germany; \\ ${ }^{5}$ Department of Biochemistry and Biophysics, Diabetes Center, and Comprehensive Cancer Center, University of California \\ at San Francisco, San Francisco, California 94143, USA
}

Multiple types of degradative enzymes, including cathepsins of the cysteine protease family, have been implicated in the regulation of angiogenesis and invasion during cancer progression. Several cysteine cathepsins are up-regulated in a mouse model of pancreatic islet cell carcinogenesis (RIP1-Tag2), and tumor progression is impaired following their collective pharmacologic inhibition. Using null mutations of four of the implicated cysteine cathepsins, we have now dissected their individual roles in cancer development. Mutants of cathepsins $B$ or $S$ impaired tumor formation and angiogenesis, while cathepsin $B$ or $L$ knockouts retarded cell proliferation and tumor growth. Absence of any one of these three genes impaired tumor invasion. In contrast, removal of cathepsin $C$ had no effect on either tumor formation or progression. We have identified E-cadherin as a target substrate of cathepsins B, L, and S, but not cathepsin C, potentially explaining their differential effects on tumor invasion. Furthermore, we detected analogous increases in cathepsin expression in human pancreatic endocrine neoplasms, and a significant association between increased levels of cathepsins $B$ and $L$ and tumor malignancy. Thus individual cysteine cathepsin genes make distinctive contributions to tumorigenesis.

[Keywords: Cancer; mouse models; proteases; cysteine cathepsins; tumor microenvironment; pancreatic endocrine cancer]

Supplemental material is available at http://www.genesdev.org.

Received October 3, 2005; revised version accepted January 6, 2006.

Cathepsin cysteine proteases have been implicated in processes important for tumor development and progression, including angiogenesis, cell proliferation, apoptosis, and invasion (B. Turk et al. 2002; Rao 2003; Jedeszko and Sloane 2004; Joyce and Hanahan 2004; Joyce et al. 2004). The human cysteine cathepsin family comprises 11 genes (cathepsins $\mathrm{B}, \mathrm{C}, \mathrm{H}, \mathrm{F}, \mathrm{K}, \mathrm{L}, \mathrm{O}, \mathrm{S}, \mathrm{V}, \mathrm{W}$, and $\mathrm{X} / \mathrm{Z}$ ), encoding intracellular proteases that are crucially important for terminal protein degradation in the acidic environment of lysosomes (V. Turk et al. 2002). Cysteine cathepsins are also recognized to have many additional functions in normal cells. For example, they are required for the processing of proteins such as enkephalin in hormone secretory granules (Yasothornsrikul et al. 2003), and of transcription factors like CDP/Cux in the nucleus (Goulet et al. 2004).

Corresponding authors.

${ }^{6}$ E-MAIL joycej@mskcc.org; FAX (212) 717-3298.

${ }^{7}$ E-MAIL dh@biochem.ucsf.edu; FAX (415) 731-3612.

Article published online ahead of print. Article and publication date are at http://www.genesdev.org/cgi/doi/10.1101/ gad.1407406.
Furthermore, the analysis of mice mutant in individual cysteine cathepsins, although viable and fertile, has uncovered specific physiological functions for several family members. For example, cathepsin $L$ mutant mice have defects in epidermal homeostasis and in regulation of the hair cycle (Roth et al. 2000) and develop cardiomyopathy with age (Stypmann et al. 2002). Cathepsin $K$-deficient mice develop osteopetrosis due to impaired osteoclastic resorption of bone matrix (Saftig et al. 1998). Mice deficient in the other cysteine cathepsins have more subtle defects, such as a failure to activate granzymes A and B in the cytotoxic lymphocytes of $\mathrm{ca}$ thepsin C mutant mice (Pham and Ley 1999), or decreased MHC class II antigen presentation in cathepsin S-deficient mice (Shi et al. 1999). Cathepsin B mutant mice can only be distinguished from their wild-type littermates when subjected to pathologic stress, such as experimental pancreatitis (Halangk et al. 2000) or liver injury (Guicciardi et al. 2001), to which they are resistant. However, when mice are deficient in both cathepsins $B$ and $L$, they die shortly after birth with severe brain atrophy associated with select neuronal loss in the cere- 
bral cortex and in the cerebellar Purkinje and granule cell layers (Felbor et al. 2002), clearly implicating redundant actions of both enzymes in maintenance of the central nervous system.

Increased levels of cysteine cathepsin expression and activity have been detected in several human and mouse cancers (Jedeszko and Sloane 2004; Joyce et al. 2004). In addition, in some cancer cells, cathepsins are mislocalized from their normal intracellular compartments to the cell surface, and can be secreted into the extracellular milieu (Mort et al. 1985; Mai et al. 2000). This redistribution of cathepsins has also been observed in normal cells; for example, cathepsin B traffics to the cell surface in cytotoxic $\mathrm{T}$ lymphocytes following degranulation (Balaji et al. 2002).

Six cathepsin family members (B, C, H, L, S, and Z) are specifically up-regulated as tumors develop in the RIP1Tag2 (RT2) mouse model of pancreatic islet carcinogenesis (Joyce et al. 2004). Analysis of the constituent cell types of these tumors revealed that cathepsin L was expressed predominantly in the cancer cells, whereas cathepsins $\mathrm{C}$ and $\mathrm{H}$ were exclusively found in innate immune cells. Cathepsin S was expressed in the infiltrating, proangiogenic $\left(\mathrm{Grl}^{+} / \mathrm{Macl}^{+}\right)$innate immune cells, and to a lesser extent in endothelial cells, while cathepsins $\mathrm{B}$ and $\mathrm{Z}$ were broadly expressed in cancer cells, endothelial cells, and immune cells (Joyce et al. 2004). When cysteine cathepsin activity was inhibited in this model, using a pan-cathepsin inhibitor ("JPM"), we observed defects in tumor growth, invasion, and angiogenesis (Joyce et al. 2004). While the pharmacological studies revealed the functional importance of cathepsins in cancer, these experiments did not allow us to assign specific functions to individual cathepsin enzymes. Therefore, we have now used a genetic approach to define the individual roles of cathepsins $\mathrm{B}, \mathrm{C}, \mathrm{L}$, and $\mathrm{S}$ in cancer. Furthermore, we show that increased expression of cathepsins B and L correlates with tumor invasion and metastasis in human pancreatic endocrine tumors.

\section{Results}

Stage-dependent effects of cathepsin mutants on RIP1-Tag2 tumor progression

Of the six cysteine cathepsin family members we had previously implicated in tumorigenesis, gene knockout mice have been generated for cathepsins $B, C, L$, and $S$. Mice mutant for each of these genes are viable, fertile, and lack gross developmental defects (Pham and Ley 1999; Shi et al. 1999; Halangk et al. 2000; Roth et al. 2000; Reinheckel et al. 2001). We generated congenic mice for each individual cathepsin knockout and crossed them to congenic RIP1-Tag2 (RT2) mice (all in the C57BL/6 background) (see Materials and Methods). RT2 transgenic mice develop multiple pancreatic islet tumors by 12-14 wk of age, as a consequence of expressing the SV40 T antigen (Tag) oncogenes in insulin-producing $\beta$-cells (Hanahan 1985). Tumor development in these mice proceeds through a series of discrete stages. Ap- proximately $50 \%$ of the $\sim 400$ islets in the pancreas become hyperproliferative, of which a subset $(-25 \%)$ subsequently acquire the ability to switch on angiogenesis (Folkman et al. 1989). Some of these angiogenic islets $(15 \%-20 \%)$ progress into cancers that can be classified as either encapsulated tumors or invasive carcinomas (Lopez and Hanahan 2002).

We first evaluated angiogenic switching (at $10.5 \mathrm{wk}$ of age) in all four homozygous cathepsin knockout RT2 mice in comparison to control RT2 littermates (cathepsin +/- RT2 and cathepsin +/+ RT2). RT2 mice mutant for cathepsin B (CtsB $B^{-/-}$RT2) showed a $24 \%$ reduction $(P=0.0086)$ in angiogenic switching when compared with RT2 littermate controls at 10.5 wk (Fig. 1A). Similarly, cathepsin $S$ mutant RT2 mice $\left(\mathrm{CtsS}^{-{ }^{--}} \mathrm{RT} 2\right)$ had a $24 \%$ reduction in angiogenic switching $(P=0.0066)$. However, ablation of cathepsin $C\left(\mathrm{Cts}^{-\mathrm{I}^{-}} \mathrm{RT} 2\right)$ or $\mathrm{ca}$ thepsin $L\left(C t s L^{-1-}\right.$ RT2) had no significant effect on the development of these precursor lesions. This result is consistent with our previous finding that neither cathep-
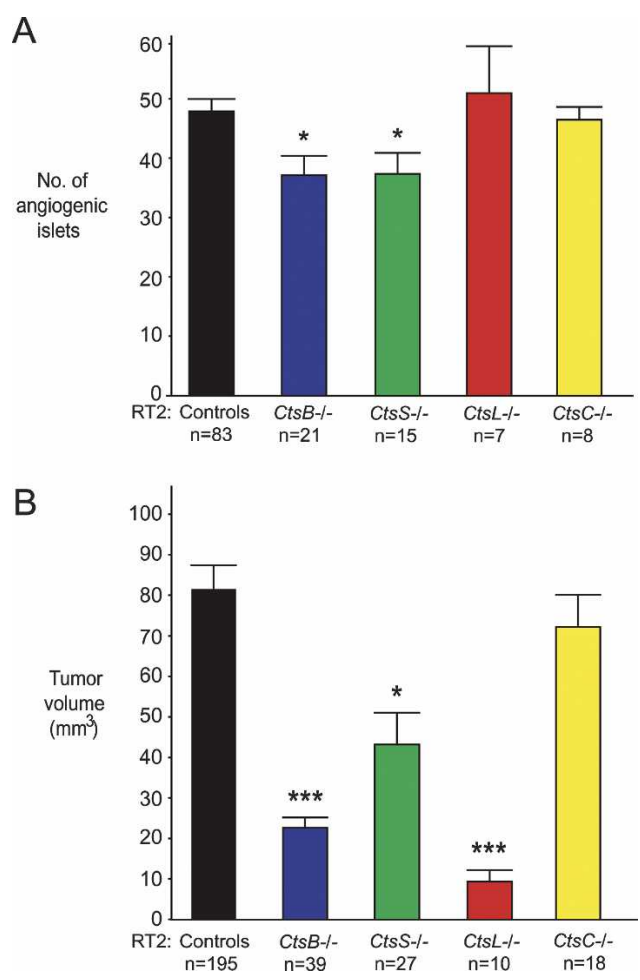

Figure 1. Differential effects of cysteine cathepsin knockouts on angiogenic switching and tumor growth. (A) Angiogenic switching was assessed in RIP1-Tag2 (RT2) mice at $10.5 \mathrm{wk}$ of age by counting the number of angiogenic islets from each individual pancreas and comparing cathepsin knockout RT2 mice to RT2 littermate controls (cathepsin +/+ and +/- littermates) of the same age. $(B)$ The cumulative tumor volume for all tumors in the pancreas was calculated for each RT2 mouse at $13.5 \mathrm{wk}$ of age and grouped by genotype. In both graphs, the means and standard errors are shown, and $P$ values were calculated by comparison to the RT2 littermate control group, using the Wilcoxon $t$-test; $\left.\left.\right|^{* \star \star}\right) P$ value of $\left.<0.0001 ;\left.\right|^{\star}\right) P$ value of $<0.01$. The numbers of mice evaluated are indicated below each genotype. 
sin $\mathrm{C}$ nor $\mathrm{L}$ is detected in the hyperplastic precursor lesions that undergo angiogenic switching (Joyce and Hanahan 2004; Joyce et al. 2004).

We next assessed the cumulative tumor volume in $c a$ thepsin mutant RT2 mice at later stages (13.5 wk of age), which revealed more pronounced differences between cathepsin family members (Fig. 1B). When compared with 13.5-wk-old RT2 littermates, both $\mathrm{CtsB}^{-/-} \mathrm{RT} 2$ (72\% decrease, $P<0.0001)$ and $C t s L^{-/-}$RT2 mice $188 \%$ decrease, $P<0.0001$ ) had substantial reductions in tumor volume. $\mathrm{CtsS}^{-1-} \mathrm{RT} 2$ mice had a less pronounced decrease in tumor volume of $47 \%(P=0.0012)$, whereas there was no significant effect on tumor growth in $\mathrm{Cts}^{-/-} \mathrm{RT} 2$ mice. These phenotypic effects are collectively consistent with our previous findings that angiogenic switching and tumor growth were reduced in RT2 mice treated with a pan-specific cathepsin protease inhibitor (Joyce et al. 2004). The quantitation of angiogenic switching and tumor volume did not reveal any statistically significant differences among any of cathepsin $+/$ RT2 or cathepsin +/+ RT2 littermates generated from all four crosses (all congenic in the C57BL/6 background). The complete data sets are shown in Supplementary Tables 1 and 2, and the quantitation of angiogenic switching and tumor volume for individual animals is shown in Supplementary Figure 1.
We then examined the effects of cathepsin gene ablation on key parameters of tumorigenesis: angiogenesis, apoptosis, cell proliferation, and tumor invasion.

Tumor vascularity was reduced in $\mathrm{CtsB}^{-/-}$and $\mathrm{CtsS}^{-/-}$ but not $\mathrm{CtsC}^{-/-}$or $\mathrm{CtsL}^{-/-}$RT2 mice

The density of tumor blood vessels was assessed by perfusion of a FITC-labeled lectin through the circulatory system. The tumor microvascular density (MVD) in $\mathrm{Cts}^{-/-}$RT2 mice was considerably reduced, by $56 \%$ $(P<0.0001)$ compared with RT2 littermate controls (Fig. 2). Tumors from $C t s S^{-1-}$ RT2 mice showed a similar decrease of $48 \%(P<0.0001)$. In contrast, there were no significant effects on MVD in tumors from $\mathrm{Cts}^{-/-} \mathrm{RT} 2$ or $C t s L^{-/-}$RT2 mice. We confirmed the reductions in vascularity by immunostaining with endothelial-selective antibodies, CD31 and MECA32, and observed similar results (data not shown). The vasculature of the exocrine pancreas was not affected in any of the cathepsin knockout RT2 mice (data not shown). The reductions in tumor vascularity in the $C t s B^{-/-} \mathrm{RT} 2$ and $C t s S^{-/-} \mathrm{RT} 2$ mice closely correlate with their decreased frequency of angiogenic switching in dysplastic islet progenitor lesions (Fig. 1A), consistent with the proposition that
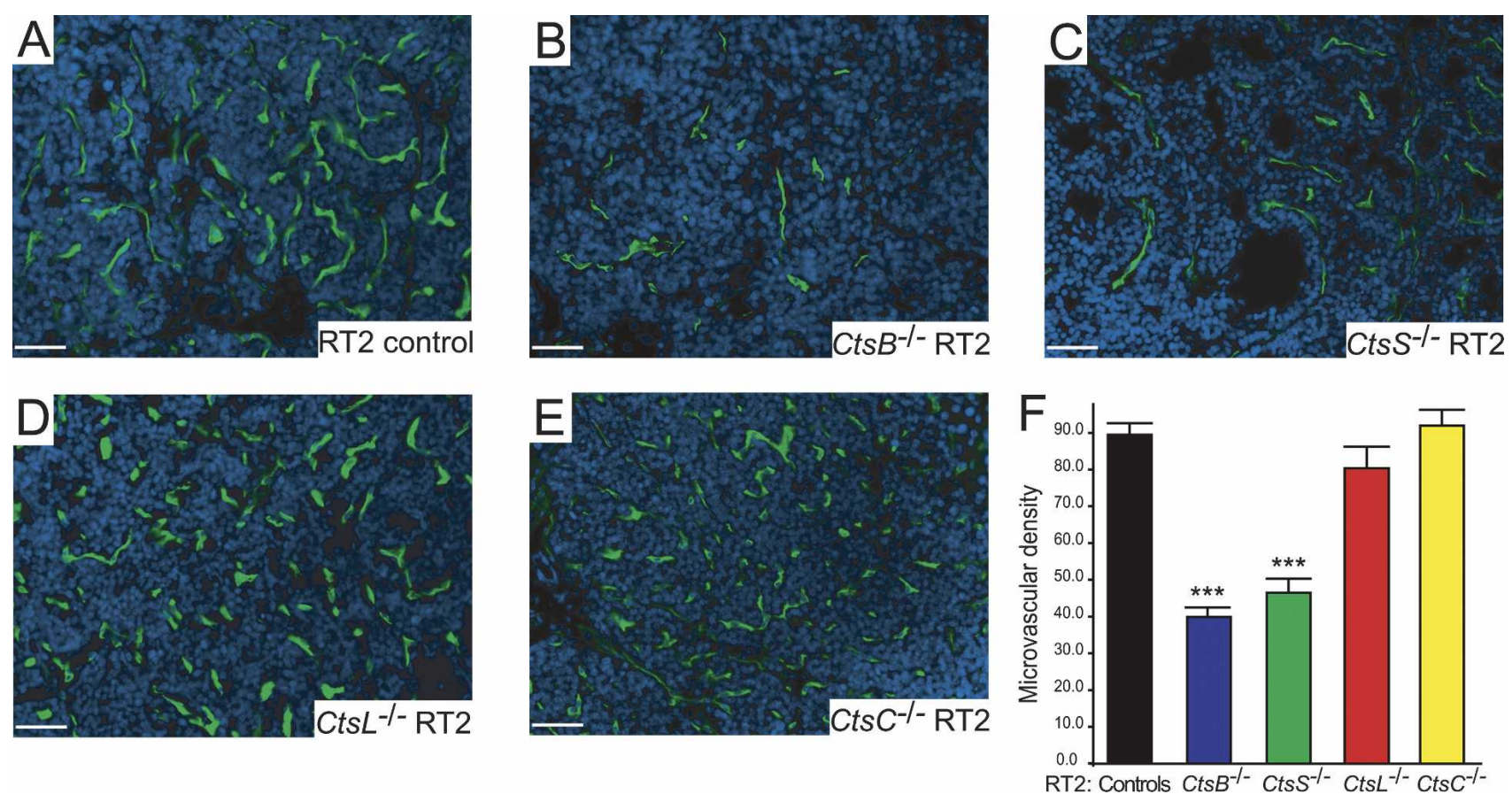

Figure 2. Deletion of cathepsins $B$ or $S$ reduces tumor vascularization. FITC-lectin injection was used to visualize the functional vasculature in tumors from wild-type control RT2 $(A), C t s B^{-/-} \mathrm{RT} 2(B), C t s S^{-/-} \mathrm{RT} 2(C), C t s L^{-/-} \mathrm{RT} 2(D)$, and $C t s C^{-/-} \mathrm{RT} 2(E)$ mice, treated under identical conditions. Representative FITC/DAPI merged images from each genotype are shown (FITC: green; DAPI: blue). $(F)$ The MVD was calculated by counting the number of vessels per field of each tumor in each mouse analyzed. The total numbers of fields scored are as follows: RT2 controls: 75 fields from nine mice; CtsB ${ }^{-/-}$RT2: 70 fields from nine mice; Cts ${ }^{-/-}$RT2: 41 fields from seven mice; $C t s L^{-/-}$RT2: 25 fields from four mice; $C t s C^{-/-}$RT2: 37 fields from three mice. The "controls" column corresponds to both +/+ and +/- RT2 littermates generated from the four cathepsin mutant/RT2 crosses. The means and standard errors are shown, and $P$ values were calculated by comparison to the RT2 littermate control group using the Wilcoxon $t$-test; $\left(^{\star \star \star}\right) P$ value of $<0.0001$. Bars, $50 \mu \mathrm{m}$. 
these cathepsins are affecting both the initial induction and the continuous maintenance of tumor angiogenesis.

\section{Increased cell death in $\mathrm{CtsB}^{-/-}$, $\mathrm{CtsL}^{-/-}$, and $\mathrm{CtsS}^{-/-}$ RT2 mice}

Defects in angiogenesis can have secondary consequences for tumor cell survival (Kerbel and Folkman 2002); thus we examined apoptosis in each cathepsin knockout/RT2 cross (Fig. 3). When compared with RT2 littermate controls, a significant increase in apoptosis was observed in tumors from $\mathrm{CtsB}^{-/-} \mathrm{RT} 2(229 \%$ increase, $P<0.0001)$ and $\mathrm{CtsS}^{-1-} \mathrm{RT} 2$ mice $(164 \%$ increase, $P<0.0001)$. Thus, increased cell death in these two $c a-$ thepsin knockout RT2 mice correlated with their observed defects in tumor angiogenesis. However, $\mathrm{CtsL}^{-/-}$ RT2 tumors had the most pronounced increase in cell death in the islet tumors $(337 \%$ increase, $P<0.0001)$, without evident defects in tumor vascularity. This result indicates there are effects on apoptosis independent of angiogenesis defects in $C t s L^{-/-}$RT2 tumors. There was a small, though not significant, increase in the number of apoptotic cells in the $\mathrm{Cts}^{-C^{--}} \mathrm{RT} 2$ tumors (25\% increase, $P=0.2791)$.

Tumor cell proliferation was reduced in $\mathrm{Cts}^{-/-}$ and $\mathrm{CtsL}^{-/-}$but not $\mathrm{CtsC}^{-/-}$or $\mathrm{CtsS}^{-/-}$RT2 mice

Given the substantial differences observed in tumor volume between the four cathepsin knockouts, we exam- ined tumor cell proliferation, which we expected to correlate with tumor growth (Fig. 4). A 44\% reduction in cell proliferation was observed in tumors from $\mathrm{CtsB}^{-/-}$ RT2 mice $(P<0.0001)$, compared with RT2 littermate controls. Tumors from $\mathrm{CtsL}^{-1-} \mathrm{RT} 2$ mice showed a more pronounced decrease of $58 \%(P<0.0001)$, which correlated closely with the substantial reduction in tumor burden in $C t s L^{-/-}$RT2 mice (Fig. 1B). In notable contrast, cell proliferation in the tumors of $\mathrm{CtsS}^{-/-} \mathrm{RT} 2$ mice was not reduced. This result was unexpected and suggests that a combination of increased cell death and impaired tumor angiogenesis accounts for the reduction in tumor growth in this knockout. There were no significant effects on cell proliferation in the $\mathrm{Cts}_{\mathrm{S}} \mathrm{C}^{-/-} \mathrm{RT} 2 \mathrm{mice}$.

\section{Tumor invasion was impaired in $\mathrm{CtsB}^{-/}, \mathrm{CtsL}^{-/-}$, and $\mathrm{CtsS}^{-/-}$RT2 mice}

Tumors in the RT2 model can be classified into three types: encapsulated tumors (Tum), microinvasive carcinomas (IC1), and highly invasive carcinomas (IC2) (Lopez and Hanahan 2002), with representative images shown in Figure 5A-C. We observed significant reductions in the formation of invasive carcinomas in $\mathrm{CtsB}^{-/-}$ RT2, CtsL ${ }^{-1-}$ RT2, and $C t s S^{-1-}$ RT2 mice $(P<0.0001$ for all three genotypes) (Fig. $5 \mathrm{H}$, with representative images in D-G). Highly invasive (IC2) tumors were never observed in the $\mathrm{CtsB}^{-/-} \mathrm{RT} 2$ mice, and only rarely in CtsL $L^{-/-}$RT2 (1.6\% of total tumors) and $\mathrm{CtsS}^{-/-}$RT2 mice
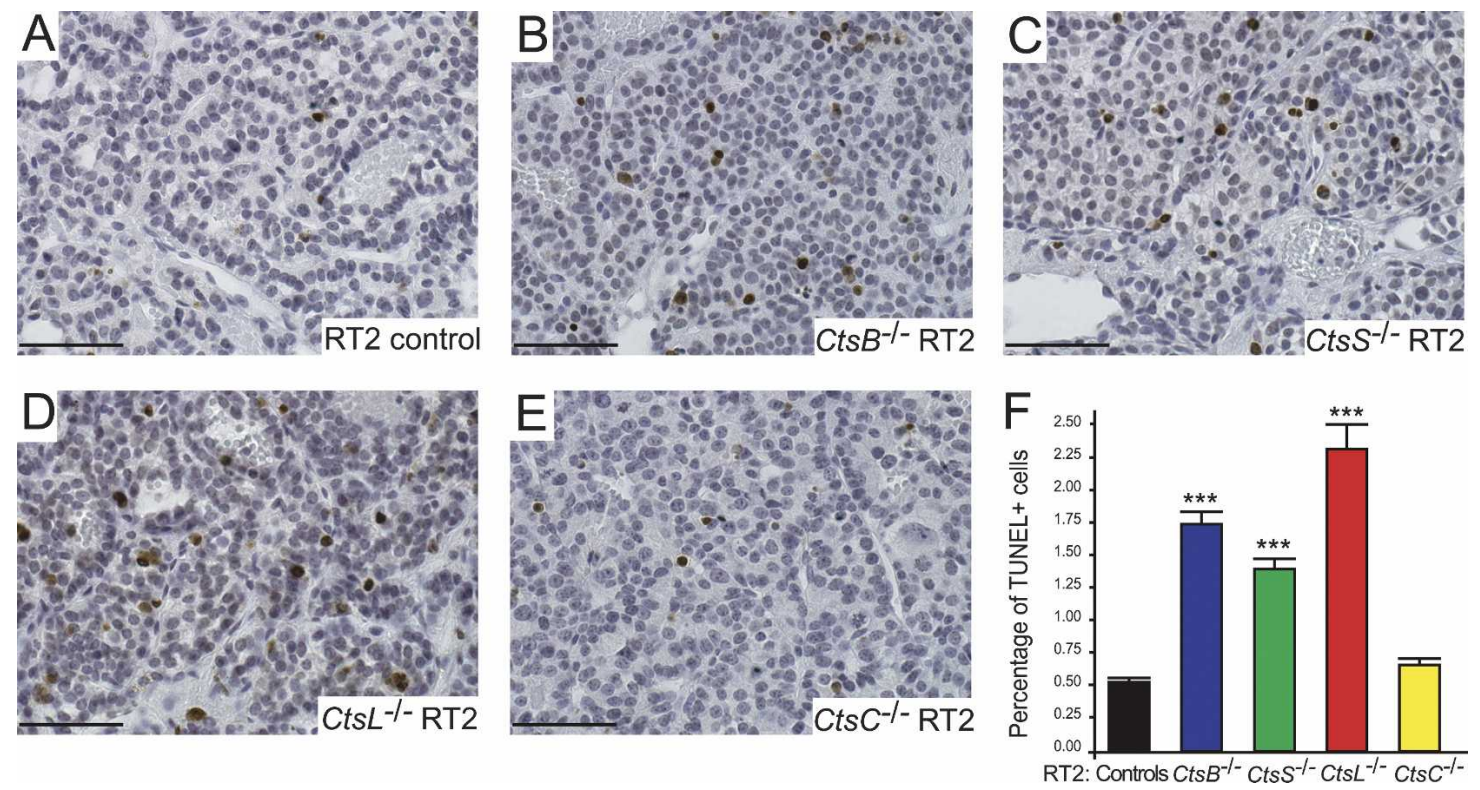

Figure 3. Deletion of cathepsins $B, L$, or $S$ significantly increases tumor cell death. TUNEL staining was used to visualize apoptotic cells in tumors from control RT2 $(A), C t s B^{-/-}$RT2 $(B), C t s S^{-/-}$RT2 $(C), C t s L^{-/-}$RT2 $(D)$, and CtsC ${ }^{-/-}$RT2 $(E)$ mice, stained under identical conditions. Positive cells are stained in brown, and hematoxylin (blue) is used as a counterstain. Representative images from each genotype are shown. (F) The percentage of apoptotic (TUNEL+) cells was calculated from several fields of each tumor in each mouse analyzed, and the means and standard errors are shown for each genotype. The total numbers of fields scored are as follows: RT2 controls: 209 fields from 21 mice; $C t s B^{-/-}$RT2: 94 fields from 10 mice; CtsS ${ }^{-/-}$RT2: 122 fields from 12 mice; CtsL $L^{-/-}$RT2: 36 fields from four mice; Cts $C^{-/-}$RT2: 86 fields from eight mice. The "controls" column corresponds to both $+/+$ and $+/-$ RT2 littermates generated from the four cathepsin mutant/RT2 crosses. The means and standard errors are shown, and $P$ values were calculated by comparison to the RT2 littermate control group using the Wilcoxon $t$-test; $\left(^{\star \star \star}\right) P$ value of $<0.0001$. Bars, $50 \mu \mathrm{m}$. 

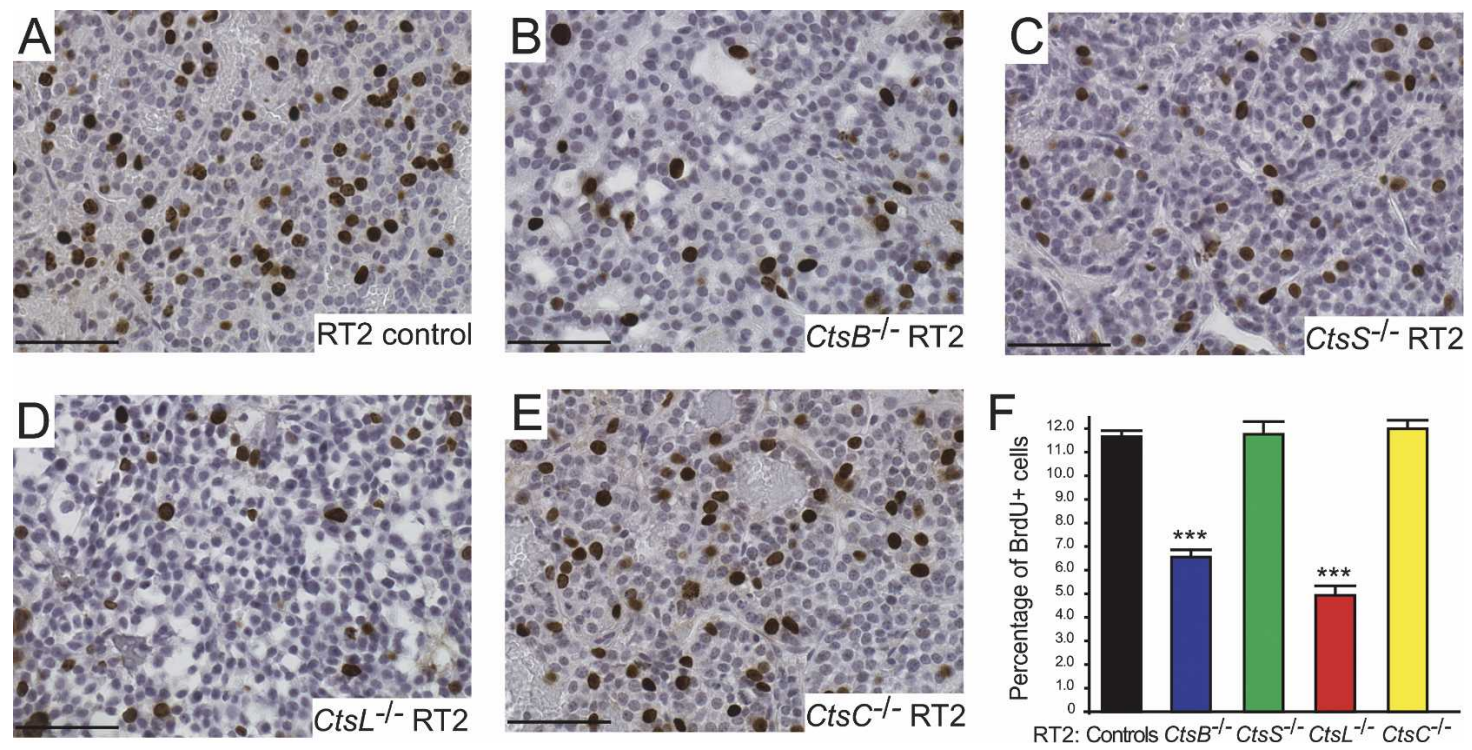

Figure 4. Mice mutant for cathepsins $B$ or $L$, but not $S$ and $C$, show decreases in tumor cell proliferation. BrdU staining was used to visualize proliferating cells in tumors from control RT2 $(A), C t s B^{-/-} \mathrm{RT} 2(B), C t s S^{-/-} \mathrm{RT} 2(C), C t s L^{-/-} \mathrm{RT} 2(D)$, and $C t s C^{-/-} \mathrm{RT} 2(E)$ mice, stained under identical conditions. Positive cells are stained in brown, and hematoxylin (blue) is used as a counterstain. Representative images from each genotype are shown. $(F)$ The percentage of proliferating (BrdU+) cells was calculated from several fields per tumor in each mouse analyzed, and the means and standard errors are shown for each genotype. The total numbers of fields scored are as follows: RT2 controls: 255 fields from 19 mice; $C t s B^{-1-}$ RT2: 81 fields from seven mice; CtsS ${ }^{-1-}$ RT2: 51 fields from five mice; Cts $L^{-1-}$ RT2: 33 fields from three mice; $C t s C^{-1-}$ RT2: 69 fields from five mice. The "controls" column corresponds to both $+/+$ and +/- RT2 littermates generated from the four cathepsin mutant/RT2 crosses. The means and standard errors are shown, and $P$ values were calculated by comparison to the RT2 littermate control group using the Wilcoxon $t$-test; $\left(^{\star \star \star}\right) P$ value of $<0.0001$. Bars, $50 \mu \mathrm{m}$.

(2.5\% of total tumors). This contrasts with the $\mathrm{Cts}^{-/-}$ RT2 mice, which had a similar tumor spectrum and number of IC2 tumors (8.7\% of total tumors) to the control littermates $(8.5 \%$ of total tumors) (Fig. $5 \mathrm{H})$. These results closely parallel our previous finding that the development of invasive carcinomas was significantly impaired in RT2 mice treated with a broad-spectrum cathepsin family inhibitor (Joyce et al. 2004). Interestingly, mutation of any one of the cathepsin $B, L$, or $S$ genes interfered with the progression to invasive carcinoma, indicating that each enzyme has an important, nonredundant role in the process of tumor invasion.

\section{E-cadherin is a target substrate of cathepsins $B, L$, and $S$}

One widely used marker of tumor invasion is the celladhesion protein E-cadherin, which is typically reduced in levels or absent in invasive tumors, as a result of mutation, transcriptional silencing, or protease-mediated ectodomain shedding (Vleminckx et al. 1991; Perl et al. 1998; Beavon 2000; Noe et al. 2001). Notably, E-cadherin down-regulation has been functionally implicated in acquisition of the invasive growth phenotype, both in the RIP1-Tag2 pathway (Perl et al. 1998) and other model systems (for review, see Cavallaro and Christofori 2004). Immunostaining for E-cadherin showed that levels of E-cadherin protein were maintained in RT2 tumors from
$\mathrm{CtsB}^{-/-} \mathrm{RT} 2, \mathrm{Cts} L^{-/-} \mathrm{RT} 2$, and $C t s S^{-/-} \mathrm{RT} 2$ mice, even in the microinvasive IC1 tumors (Fig. 6C-H). This contrasts with IC1 tumors in control RT2 mice (Fig. 6A,B) and in $\mathrm{Cts}^{-/-}$RT2 mice (Fig. 6I,J), in which down-regulation of E-cadherin, particularly at the invasive edges, was observed.

The maintenance of E-cadherin protein levels in tumors from $\mathrm{CtsB}^{-/-} \mathrm{RT} 2, \mathrm{CtsL}^{-/-} \mathrm{RT} 2$, and $\mathrm{CtsS}^{-/-} \mathrm{RT} 2$ mice motivated us to investigate whether these cathepsins might directly cleave E-cadherin so as to release the extracellular domain, thereby abrogating its adhesive (anti-invasive) function. The $\mathrm{N}$-terminal extracellular domains of E-cadherin proteins on adjacent cells bind to each other in a homophilic manner to establish cell-cell junctions (for review, see Beavon 2000). Thus, proteolysis of its extracellular domain represents an alternative to the well-documented mechanisms of mutational inactivation or transcriptional down-regulation as a means of losing E-cadherin function. Such loss of E-cadherin function by proteolysis has been demonstrated for several types of protease, including MMP3, MMP7, ADAM10, and plasmin (Lochter et al. 1997; Noe et al. 2001; Ryniers et al. 2002; Maretzky et al. 2005). In principle, cathepsins could effect E-cadherin loss of function by directly cleaving the ectodomain, or by activating other proteases to perform this task.

To test whether E-cadherin might be a direct target substrate for cysteine cathepsins, recombinant E-cad- 
Gocheva et al.
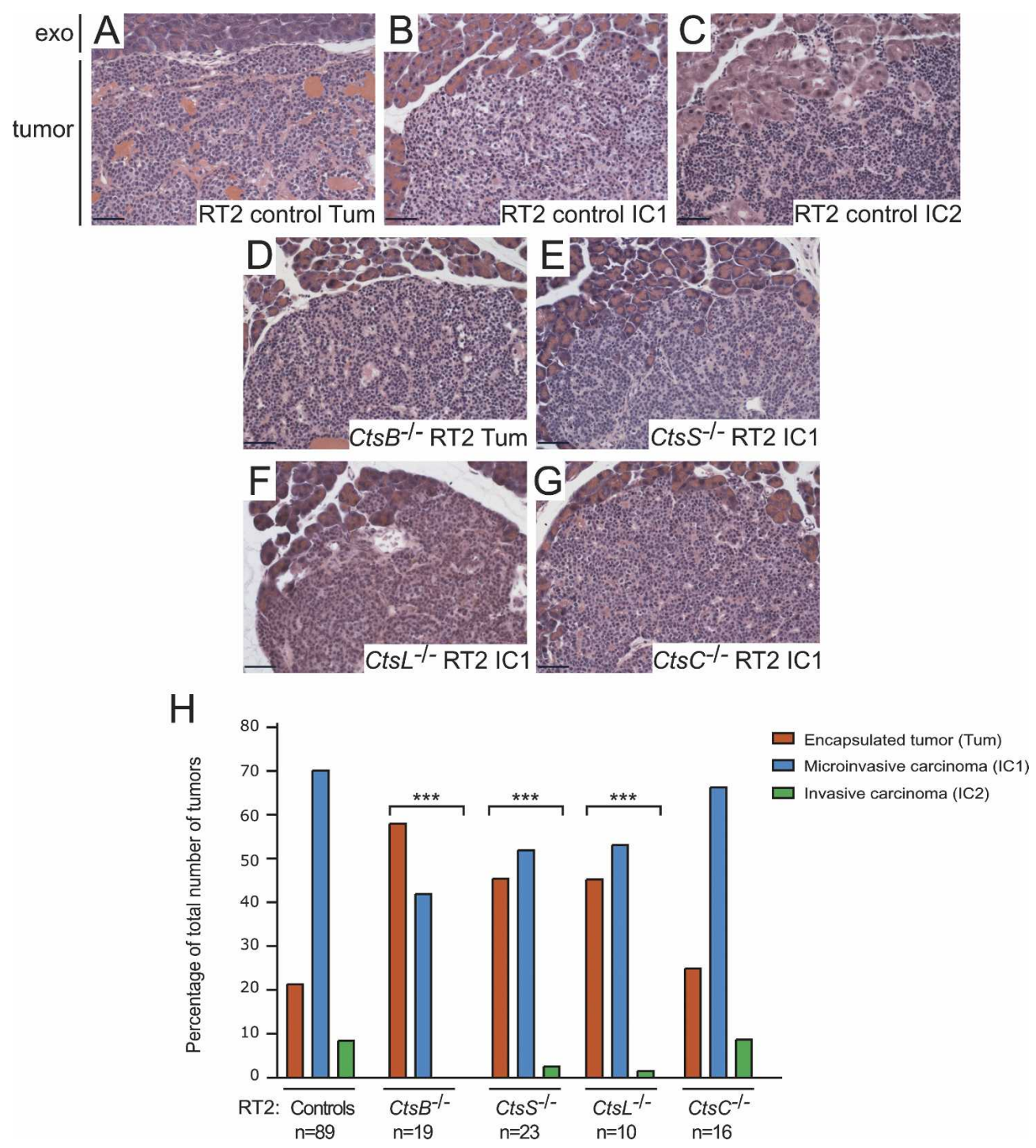

Figure 5. Deletion of cathepsins $B, L$, or $S$, but not $C$, impairs tumor invasion. H\&E staining was used to grade tumors from cathepsin knockout RT2 mice and RT2 littermate controls. Tumors in RT2 mice can be divided into three different classes, as shown in representative H\&E images from control RT2 mice: (A) Encapsulated tumors (Tum). (B) Microinvasive carcinomas (IC1). (C) Invasive carcinomas (IC2). Representative images for the predominant grade of tumors in cathepsin knockout/RT2 mice are indicated. $(D)$

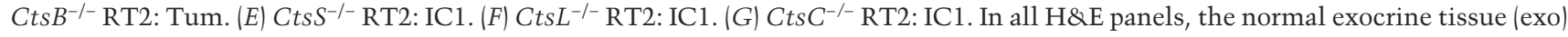
is shown at the top of the image for comparison to the tumor below. $(H)$ Graph showing the relative proportions of encapsulated, microinvasive, and invasive carcinomas in RT2 controls versus the different cathepsin knockout/RT2 mice at 13.5 wk of age. The "controls" column corresponds to both +/+ and +/- RT2 littermates generated from the four cathepsin mutant/RT2 crosses. The total numbers of tumors scored are as follows: controls: 1416 tumors from 89 mice; CtsB $^{-/-}$RT2: 269 tumors from 19 mice; CtsS ${ }^{-/-}$RT2: 277 tumors from 23 mice; CtsL ${ }^{\prime-}$ RT2: 64 tumors from 10 mice; $C t s C^{-/-}$RT2: 288 tumors from 16 mice. The distribution of tumor types in the control group was compared with the distribution of tumors in the other four groups using a cumulative logit model with generalized estimating equations to correct for correlations within individual mice. $\left(^{\star \star \star}\right) P$ value of $<0.0001$ compared with the controls group using this test. Bars, $50 \mu \mathrm{m}$.

herin was incubated with each of the active cathepsin enzymes (cathepsin B, C, L, or S) in vitro under defined conditions, followed by Western blotting. The data clearly reveal that E-cadherin is specifically cleaved by cathepsins B, L, or S, but not by cathepsin C (Fig. 6K).

A set of distinctive antibodies was used to demonstrate specific cleavage of E-cadherin in the extracellular portion of the protein by cathepsins $B$, L, or S, but not by cathepsin C (Fig. 6K): The MAb ECCD2 recognizes an epitope in the EC1 extracellular subdomain of E-cadherin; the MAb HECD-1 binds the EC2 extracellular subdomain; while anti-human polyclonal IgG-Fc detects an IgG linker domain near the $\mathrm{C}$ terminus of the recombinant E-cadherin protein. Several cleaved E-cadherin fragments of $\sim 64 \mathrm{kDa}$ and $30-35 \mathrm{kDa}$ were detected, depending on the antibody used (Fig. 6K). We confirmed that all 

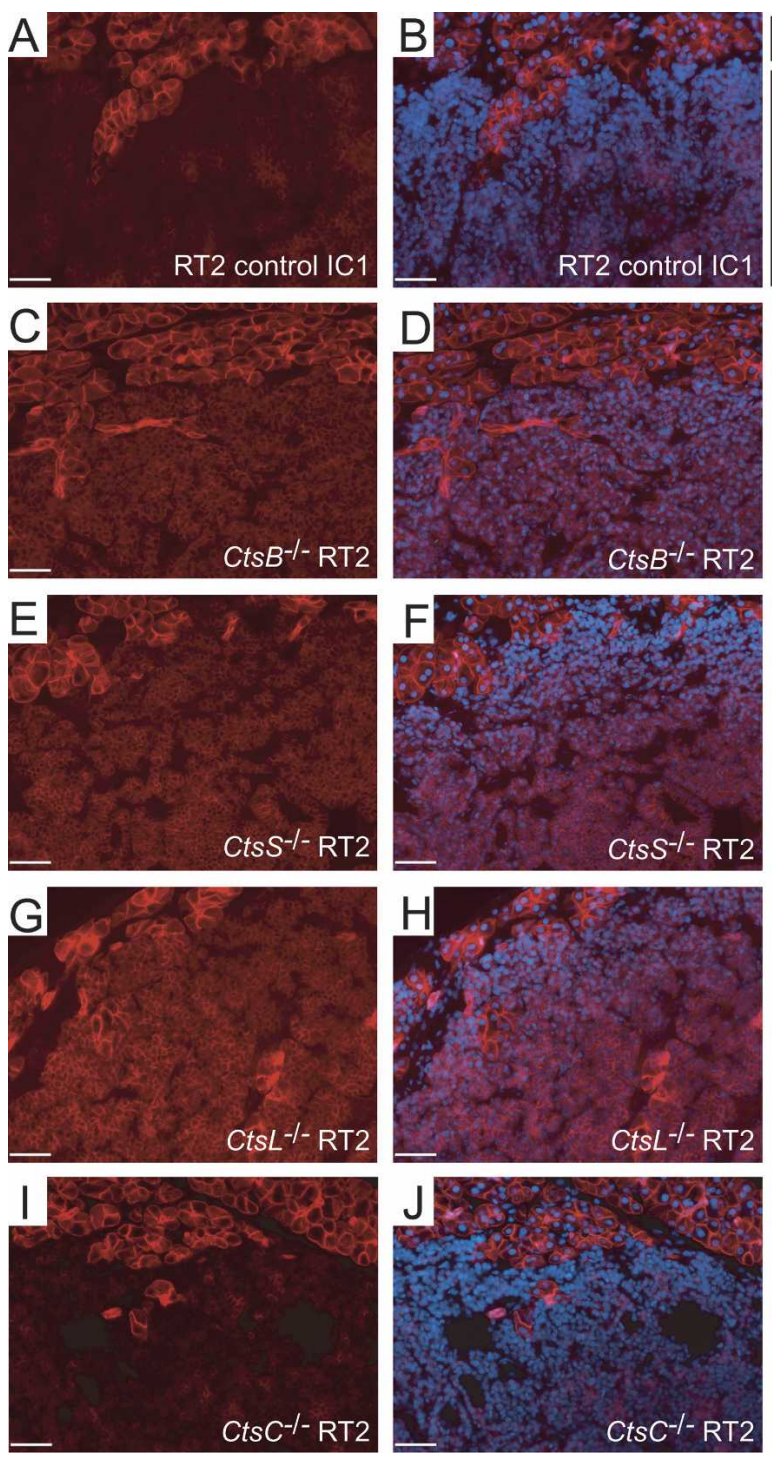
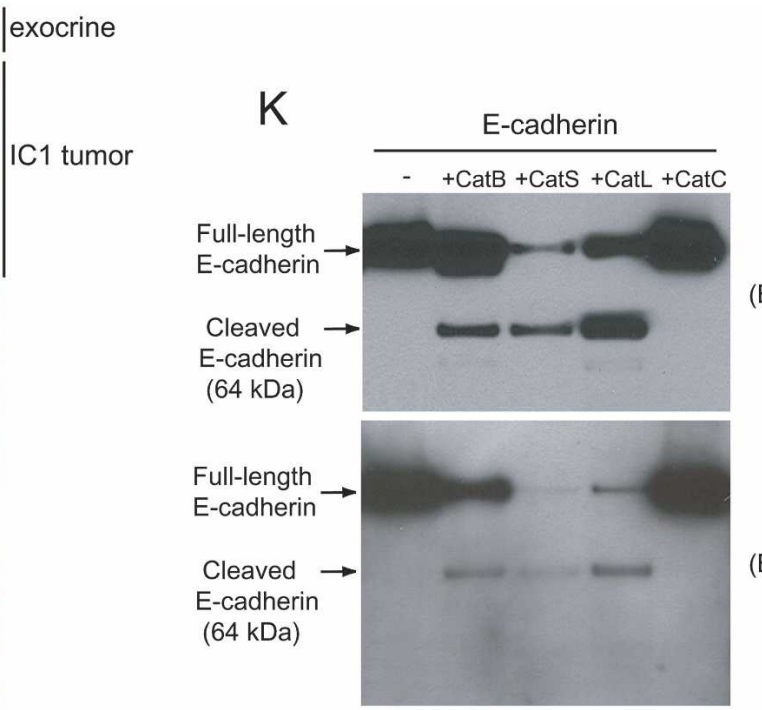

ECCD2

(E-cadherin EC1 subdomain)

Figure 6. E-cadherin is a target substrate for cathepsins B, L, or S, but not C, in vivo and in vitro. E-cadherin staining was used to confirm the $\mathrm{H} \& \mathrm{E}$ grading and revealed a consistent maintenance of E-cadherin levels even in microinvasive carcinomas (IC1) from $C t s B^{-/-} \mathrm{RT} 2(C, D), C t s S^{-/-} \mathrm{RT} 2(E, F)$, and $C t s L^{-/-} \mathrm{RT} 2(G, H)$ mice, but not in $C t s C^{-/-} \mathrm{RT} 2(I, J)$ or control RT2 $(A, B)$ IC1 tumors. E-cadherin-stained images (red) are shown in the left panels, with E-cadherin/DAPI merged images in the right panels. The normal exocrine tissue (in which levels of E-cadherin are the same in all genotypes) is shown at the top of the image for comparative reference to the IC1 tumor below. Bars, $50 \mu \mathrm{m}$. $(K)$ Recombinant E-cadherin is cleaved by cathepsins $\mathrm{B}, \mathrm{L}$, and $\mathrm{S}$, but not cathepsin $\mathrm{C}$ in vitro. E-cadherin was incubated under identical conditions with each activated cathepsin, as indicated above the top panel, and Western blots were hybridized with HECD-1 (E-cadherin extracellular subdomain EC2), ECCD2 (extracellular subdomain EC1), or IgG (to detect recombinant E-cadherin, which has an IgG linker at the $\mathrm{C}$ terminus). Full-length and cleaved E-cadherin fragments are indicated at the left side.

four purified cathepsin enzymes (in particular, cathep$\sin$ C) were, indeed, active as proteases by incubating an aliquot of each with fluorogenic peptide substrates (Supplementary Fig. 2) immediately before performing the E-cadherin cleavage assay.

\section{Evaluation of cathepsin expression in mouse islet tumor sections}

To substantiate and extend upon the analysis of celltype-specific expression of the individual cathepsins pre- viously discerned by flow cytometry (Joyce et al. 2004), and to set the stage for cross-correlative analysis of archival human tumor samples, we analyzed cathepsin expression patterns in RT2 tissue sections by immunostaining with specific antibodies (Fig. 7). The data reveal that in mouse RT2 tumors, cathepsin B was expressed to different degrees by all three cell types (tumor, endothelial, and immune) (Fig. 7E), cathepsin L was predominantly expressed by tumor cells (Fig. 7F), cathepsin S was expressed by endothelial cells and associated innate immune cells (Fig. 7G), and cathepsin $\mathrm{C}$ was apparently 


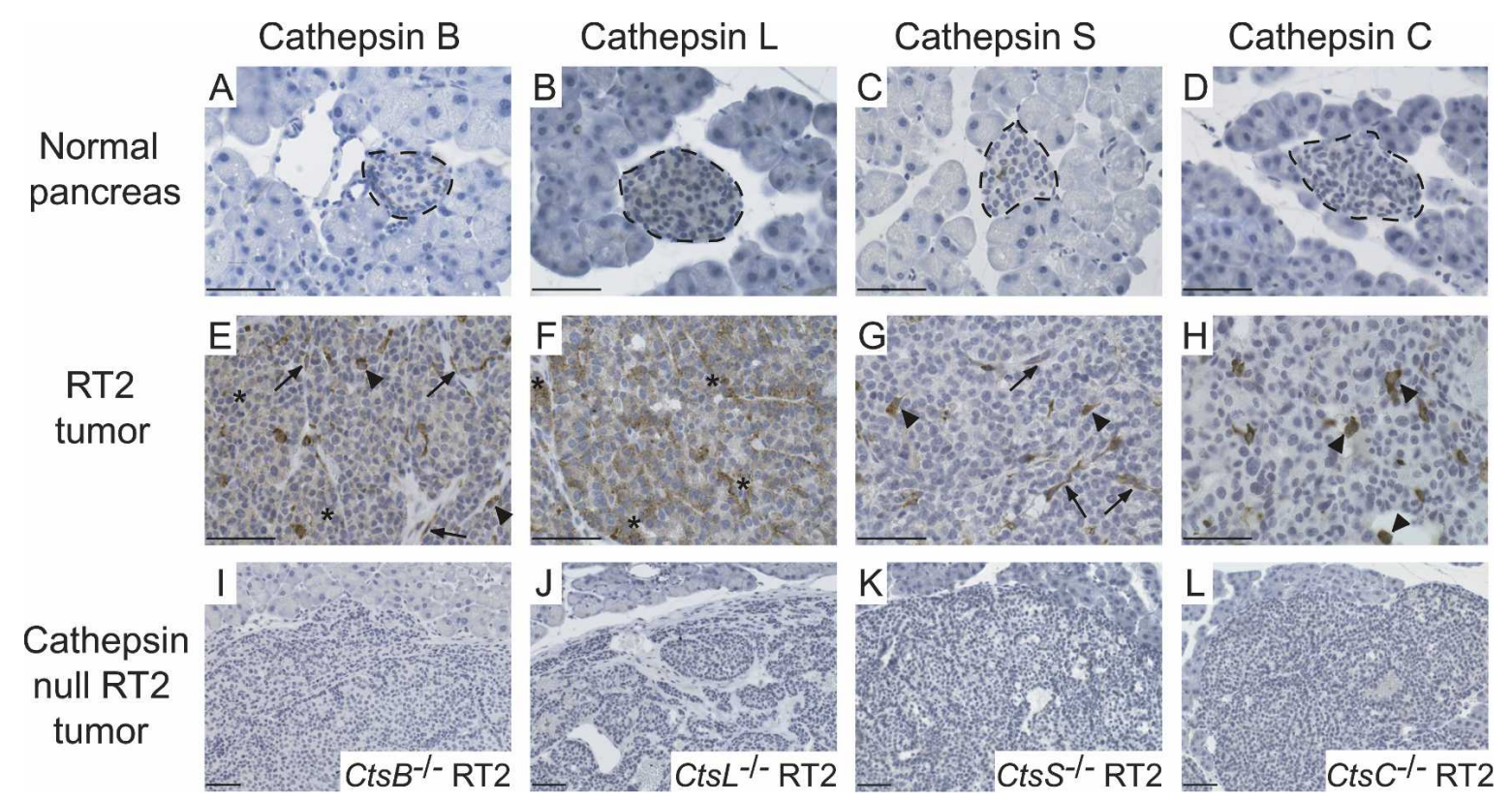

Figure 7. Cell-type-specific expression of cathepsins in mouse RT2 pancreatic tumors. Normal pancreas and RT2 tumors were stained with antibodies against cathepsins $\mathrm{B}, \mathrm{L}, \mathrm{S}$, and $\mathrm{C}$ as indicated. $(A-D)$ Representative images of normal mouse pancreas stained for each antibody are shown in the first row, with normal islets indicated with a dotted black line, surrounded by normal exocrine cells. $(E-H)$ Representative images of RT2 tumors stained for each antibody are shown in the second row. Cathepsin-positive cells are stained in brown, and hematoxylin (blue) was used as a counterstain. Tumor cell staining is indicated by asterisks, endothelial cell staining by arrows, and immune cell staining by arrowheads. $(I-L)$ The specificity of antibodies against cathepsins B, C, L, and S is demonstrated by the absence of staining in the corresponding cathepsin-null/RT2 tumors, as indicated in the third row. Bars, $50 \mu \mathrm{m}$.

associated with infiltrating immune cells (Fig. 7H). Thus, in addition to a general up-regulation in cathepsin protein levels when normal islets and RT2 tumors are compared (Fig. 7), these immunostaining data are completely consistent with our previous analyses of cell-specific cathepsin expression using flow cytometry (Joyce et al. 2004).

\section{Cathepsins B and $L$ are up-regulated in human pancreatic endocrine tumors}

To address the prospect that our findings of distinctive roles for specific cathepsin genes might be predictive of similar involvements in human cancers, we examined cathepsin expression in human pancreatic endocrine neoplasms (PEN). PEN are rare epithelial tumors that can be broadly classified as either benign or malignant, and functional or nonfunctional (Hochwald et al. 2002). Functional tumors have a clinical syndrome because of excess hormone secretion, and include insulinomas, gastrinomas, and glucagonomas among others, with insulinomas constituting the majority (Viola and Sosa 2005). Most insulinomas develop sporadically, but a small proportion arise as part of the hereditary multiple endocrine neoplasia type 1 (MEN1) syndrome. While the MEN1 gene, encoding menin, is mutated in most hereditary cases, MEN1 mutations are rare in the sporadic insulinomas analyzed to date (four mutations in 105 cases) (Zhuang et al. 1997; Shan et al. 1998; Cupisti et al. 2000;
Jonkers et al. 2005); thus little is currently known about the molecular mechanisms underlying the majority of sporadic insulinomas.

A tissue microarray (TMA) was constructed, composed of normal pancreas tissue controls and 80 PEN, the majority of which were insulinomas, islet cell tumors, and associated metastatic lesions. We performed immunostaining for cysteine cathepsins $\mathrm{B}, \mathrm{C}, \mathrm{L}$, and $\mathrm{S}$ and scored each lesion based on staining intensity (see Materials and Methods). For those tumors with extensive pathology records $(n=74)$, we grouped PEN lesions into four classes. Benign tumors were classified as lesions in which there was no evidence of either tumor or vascular invasion (Benign, $n=22$ ). Vascular invasive tumors were classified by the presence of tumor cells or tumor emboli in the blood or lymphatic vasculature (Vascular Invasive, $n=12$ ). Invasive tumors were classified into two groups: those showing either frank tumor cell invasion, but no evidence of metastases (Invasive Tumor, $n=11$ ), or those in which the primary PEN lesion had metastasized to a secondary organ (Metastatic Primary, $n=23$ ). Finally metastases, to the liver and/or lymph nodes, were also scored (Metastasis, $n=6$ ).

We found that cathepsins B and L were progressively up-regulated as PEN become more aggressive, when compared with normal islets and the exocrine pancreas (Fig. 8A-F,G-L). For both proteins, this gradual increase in immunostaining was statistically significant (Fig. 8Y) $(P<0.0001$ for both $)$. In contrast, cathepsin S immuno- 


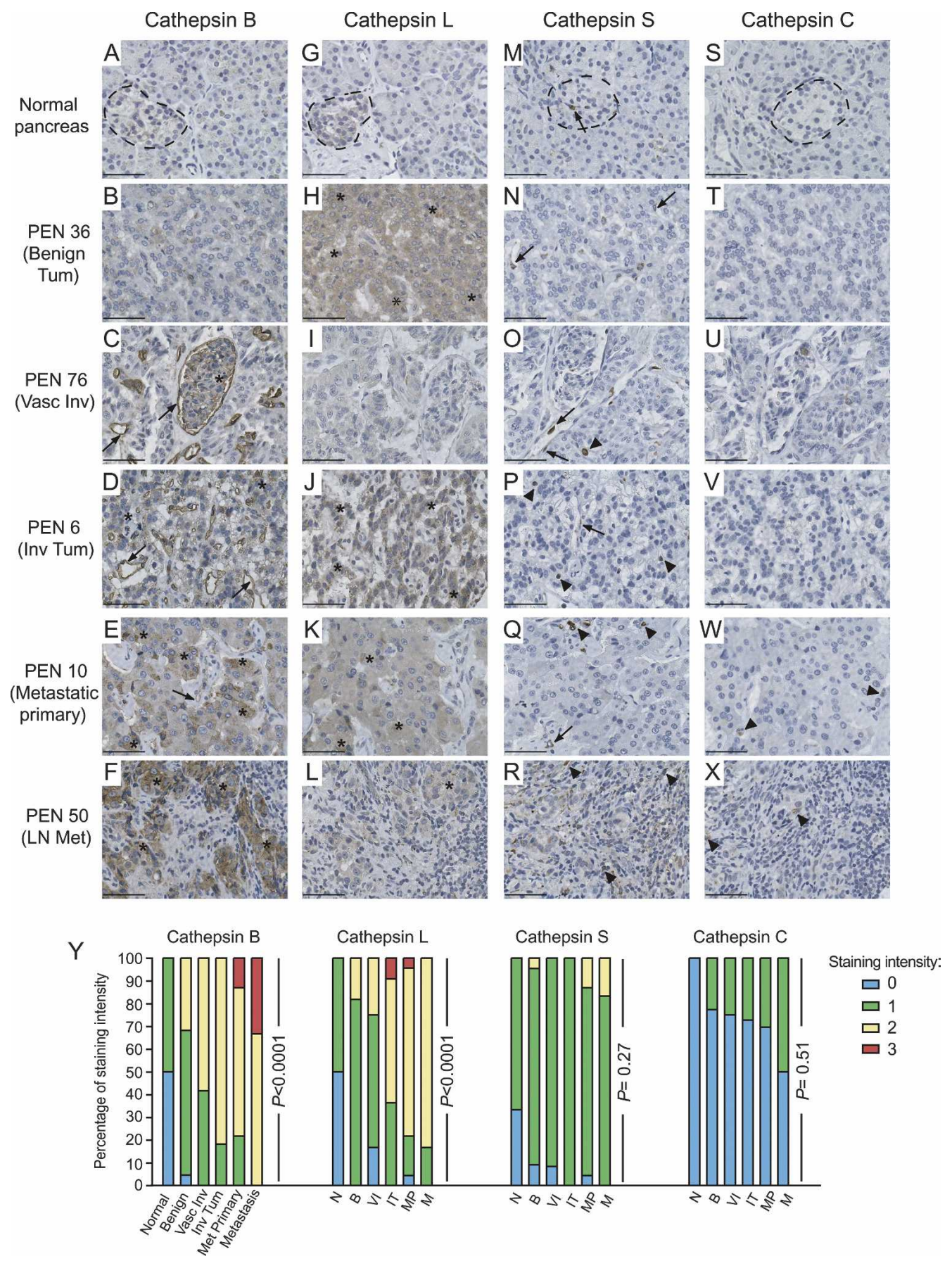

Figure 8. Increased levels of cathepsins B and L are positively associated with tumor progression in human PEN lesions and associated metastases. A TMA was constructed from a panel of human PEN and normal pancreas tissues. $(A-X)$ Tissue arrays were stained with antibodies against cathepsins B, L, S, and C as indicated. Cathepsin-positive cells are stained in brown, and hematoxylin (blue) was used as a counterstain. Representative images of normal human pancreas $(n=6)$ stained for each antibody are shown in the first row, with normal islets indicated with a dotted black line, surrounded by normal exocrine cells. Representative images for each of the tumor stages-Benign Tumor $(n=22)$, Vascular Invasive Tumor $(n=12)$, Invasive Tumor $(n=11)$, Metastatic Primary $(n=23)$, and Metastasis $(n=6)$-are shown in the rows below. The PEN number corresponds to the position on the tissue array. Tumor cell staining is indicated by asterisks, endothelial cell staining by arrows, and immune cell staining by arrowheads. $(Y)$ The cathepsin staining for each tissue specimen was scored as negative (0) or positive [three levels: weak (1); moderate (2); strong (3)] and graphed as the percentage of staining intensity for each stage. For each cathepsin, an overall test of differences among any of the groups (normal and tumor) was performed. An exact version of Mantel Haenszel's test for trend was performed to look for differences in staining in each tumor group compared with the normal controls and to calculate $P$ values, which are shown next to each data set. Bars, $50 \mu \mathrm{m}$. 
staining was only weakly positive in PEN lesions (Fig. $8 \mathrm{M}-\mathrm{R}$ ) and did not show an association with tumor malignancy (Fig. 8Y) $(P=0.27)$. Similarly, cathepsin $\mathrm{C}$ was either not expressed or weakly expressed at all stages (Fig. 8S-X), and the level of staining did not appreciably increase as tumors progressed (Fig. $8 \mathrm{Y})(P=0.51)$. The detailed statistical analysis of cathepsin staining across all groups is shown in Supplementary Table 3.

TMAs have been extensively used in recent years, and multiple studies have addressed the valid concern that 0.60-mm "cores" may not be representative of entire tissues or tumor samples (for review, see Simon and Sauter 2003). Several studies have compared immunostaining in TMAs versus large tissue sections and the consensus is of a high concordance between the results obtained from the different procedures (for review, see Simon and Sauter 2003). Increasing the number of tissue cores provided more representative information than if a single core was used, although adding more than four samples had little additional effect on the concordance level (Camp et al. 2000; Simon and Sauter 2003). In this study, we used TMAs constructed using three core samples per tumor or control tissue, and found complete concordance in the cathepsin staining, both in terms of intensity of staining and the cell type(s) that were positive. Furthermore, for several cases, we were able to immunostain the entire tumor specimen from which the three cores had been sampled, and again found a complete correlation between the two approaches (data not shown).

Notably, the expression and localization of cathepsins $\mathrm{B}$ and $\mathrm{L}$ in human PEN lesions is consistent with the immunostaining of RT2 tumors (Fig. 7), and with our previous data describing expression profiles of the individual cathepsins in constituent cell types purified from RT2 tumors by flow cytometry (Joyce et al. 2004). Cathepsin B was expressed by both tumor cells and endothelial cells in human PEN (Fig. 8A-F), and was particularly intense in the pancreatic tumor cells that had metastasized to the lymph nodes (Fig. 8F). Cathepsin L was predominantly expressed by tumor cells, with little or no positive staining in endothelial or immune cells in human PEN (Fig. 8G-L). Although cathepsins C and S are up-regulated in mouse islet tumors, in the human PEN lesions analyzed both proteins were either absent or expressed at low levels (Fig. 8M-R,S-X). While this may indicate a more pronounced innate immune cell infiltrate in RT2 lesions compared with most of the human PEN analyzed, it is also possible that differences in fixation methods and the antibodies used may account for the apparently weaker staining in human tissues.

\section{Discussion}

Using null mutants of cysteine cathepsin genes, we found that members of this family have distinct roles in promoting pancreatic islet tumorigenesis in the RT2 mouse model. We show that removing cathepsins $B$ or $S$ reduces the frequency of initial angiogenic switching in dysplastic progenitors, and impairs subsequent development of the tumor vasculature. We show that absence of cathepsins $B, L$, or $S$ reduced tumor growth in this model, whereas removal of cathepsin $C$, which was also up-regulated in RT2 tumors (Joyce et al. 2004), had no significant effect on any parameter of tumorigenesis examined. The marked reductions in tumor growth in $\mathrm{CtsB}^{-/-} \mathrm{RT} 2$ and $\mathrm{CtsL}^{-/-} \mathrm{RT} 2$ mice presumably resulted from decreased cell proliferation and increased apoptosis. We attribute the moderately reduced tumor growth in $\mathrm{CtsS}^{-/-} \mathrm{RT} 2$ mice to increased apoptosis and an impaired tumor vasculature, since tumor cell proliferation was unaffected. Interestingly, null mutations in any one of the three cathepsins $B, L$, or $S$ perturbed the progression to invasive carcinoma, indicating that each enzyme has an important, nonredundant role in the process of tumor invasion.

With regard to the invasive phenotype, we identified E-cadherin, a suppressor of invasive growth, as a candidate substrate that likely underlies the differential effects of cathepsins B, L, and S versus cathepsin C. We show that cathepsins B, L, and S cleave E-cadherin in vitro, whereas cathepsin $\mathrm{C}$ does not. Furthermore, when cathepsins B, L, and S are deleted in RT2 mice, there is maintenance of E-cadherin protein levels, associated with a pronounced reduction in tumor invasion in vivo. It has been hypothesized that cleavage of the extracellular domain of E-cadherin and the subsequent loss of cellcell adhesion leads to enhanced tumor invasion (for review, see Noe et al. 1999|. Now we have demonstrated that cathepsins B, L, and S can cleave E-cadherin, adding these enzymes to the list of proteases that mediate tumor invasion, at least in part, through E-cadherin proteolysis. Intriguingly, while the biochemical data suggest that any one of the three cathepsins is sufficient to cleave E-cadherin and promote invasion, the genetic data argue that their concerted actions are necessary for E-cadherin down-regulation and promotion of invasion. We foresee two likely explanations. First, the cell-cell and tissue microenvironment may require all three cathepsins in order to produce efficient extracellular proteolysis of ligated E-cadherins linking adjacent cells, with consequent loss of adhesion function and facilitation of invasiveness, whereas in vitro, acting on a pure substrate, any one of the three is capable of cleaving E-cadherin. Second, each of the three proteases may have independent substrates above and beyond E-cadherin, whose proteolysis is necessary for invasive growth and for full loss of functional E-cadherin. These mechanisms could reconcile the in vitro biochemical data and the in vivo genetic data, and deserve future investigation.

While the precise molecular mechanisms by which each cathepsin elicits its other protumorigenic functions remain to be defined, our findings have identified the stages and processes in tumorigenesis in which each plays a role. These genetic studies will enable us to design experiments aimed to elucidate the biochemical basis for the functional differences between members of a protease gene family that play distinct roles in tumor progression. There are several considerations. First, while the cathepsins we have investigated are all members of the papain family of cysteine proteases, there are 
differences in their enzymatic activities that could result in distinct substrate preferences. For example, most cysteine cathepsins (including cathepsins $\mathrm{L}$ and S) are endopeptidases, whereas cathepsin B has both endopeptidase and carboxyopeptidase activity, while cathepsin C is exclusively an aminopeptidase (Turk et al. 2001). Second, the cell type that produces each cathepsin may affect the range of substrates available, such that cathepsin B expressed by endothelial cells may have access to a very different set of targets compared with cathepsin B expressed by tumor cells. Third, the period in cancer progression during when each enzyme is expressed and active will ultimately influence the targets available in a temporal manner, and consequently the stage-specific tumorigenic processes where those enzymes could play a role.

The molecular mechanisms underlying the effector functions these proteases have on tumorigenesis may ultimately involve some combination of all three possibilities, and the results presented here point toward that conclusion. The simplest explanation, that differences in substrate specificity or mechanism of action account for the distinct functions of these enzymes, may apply in the case of cathepsin $\mathrm{C}$ versus the other three cathepsins, as we show here for E-cadherin. Importantly, targeting E-cadherin cannot be the sole manifestation of their activities in this neoplastic microenvironment. While all three enzymes evidently contribute to tumor invasion and resistance to apoptosis, only cathepsins B and S impact tumor angiogenesis, whereas only cathepsins B and $\mathrm{L}$ affect tumor cell proliferation. Moreover, the finding that only those cathepsins expressed by endothelial cells (cathepsins B and S) mediate angiogenic switching and development of the tumor vasculature suggests that the cell type that produces a particular cathepsin is also important. Similarly, cathepsins B and L are expressed in tumor cells, but cathepsin S is not-thus their removal could have a direct impact on tumor cell proliferation, whereas cathepsin S may only be able to impact tumor proliferation indirectly. Future experiments aimed to remove individual cathepsins using cell-type-specific and conditional gene deletions should help address these alternative explanations.

It is also interesting to note that while cathepsin C was identified as one of a subset of cysteine cathepsins that were up-regulated as islet tumors develop (Joyce et al. 2004), when RT2 mice carry a null mutation in this gene, there is no apparent phenotype. This result illustrates the importance of thorough functional validation for candidates arising from microarray screens of cancers as, not surprisingly, there will be genes whose expression is up-regulated as a result of changes in the transcriptional program but that do not contribute to cancer development.

Finally, our analysis of human pancreatic endocrine tumors has revealed a significant association between increased cathepsin B and L staining and progression toward malignancy. Interestingly, a recent study of sporadic insulinomas using comparative genomic hybridization (CGH) identified gain of chromosome 9q (which in- cludes the cathepsin $L$ gene) as the most frequent genomic aberration (Jonkers et al. 2005). However, it should be noted that mouse cathepsin $\mathrm{L}$ is closely related to both human cathepsin L and human cathepsin V (also known as cathepsin L2) $(72 \%$ and $75 \%$ amino acid sequence identity, respectively), thus warranting the future analysis of cathepsin $\mathrm{V}$ in islet cell tumors. The data presented here add PEN to a growing list of tumors in which increased cathepsin expression and activity are associated with more advanced and aggressive cancer (for review, see Jedeszko and Sloane 2004).

In summary, our data provide several important insights. First, they confirm and extend our previous findings that pharmacological inhibition of the cysteine cathepsin family appreciably reduces tumor formation and progression in the RT2 tumor model. Second, distinct functions in tumorigenesis can be attributed to specific cathepsin family members, excluding a role for one even though all were similarly up-regulated in tumors. Third, we have identified multiple tumorigenic processes that are impacted by different cathepsin family members. This knowledge will enable a focused search for the specific substrates of particular cathepsins that are important in angiogenesis, tumor invasion, resistance to apoptosis, or tumor cell proliferation. Fourth, we have identified E-cadherin as a target substrate for cathepsins B, L, and $S$, which may explain, in part, their proinvasive functions. Finally, we found that human pancreatic endocrine tumors up-regulate cysteine cathepsins B and L much as in the mouse model. These data may be applicable to the design of enzyme-specific cathepsin inhibitors and potentially in selecting stages of cancer progression to target for optimal efficacy; in particular, our mouse functional studies and analysis of human PEN suggest that a selective inhibitor of cathepsins B and L could have therapeutic value against invasive islet carcinomas, and perhaps other tumor types.

\section{Materials and methods}

\section{Generation and analysis of cathepsin knockout/RT2 mice}

The generation of RIP1-Tag2 (RT2) mice (Hanahan 1985) and the four cathepsin mutant mice used in this study has been previously reported (Pham and Ley 1999; Shi et al. 1999; Halangk et al. 2000; Roth et al. 2000). Each cathepsin gene knockout and RT2 mice were backcrossed into the C57BL/6 background for at least 10 generations. They were then intercrossed to generate congenic homozygous, heterozygous, and wild-type cathepsin mutants together with the RT2 transgene. Tumor volume and angiogenic islet quantitation was performed as previously described (Inoue et al. 2002; Bergers et al. 2003). All animal studies were performed using protocols approved by the animal care and utilization committees at Memorial Sloan Kettering Cancer Center (MSKCC) and the University of California at San Francisco. Data are presented as arithmetic means and standard errors. The Wilcoxon $t$-test was used for statistical comparison of groups. As the littermate controls from the four crosses were pooled, a stricter $P$ value of $<0.01$ was considered significant. 


\section{Immunohistochemistry: staining and analysis}

Tissues were prepared as previously described for frozen and paraffin embedding (Lopez and Hanahan 2002). FITC-lectin, BrdU, TUNEL, and E-cadherin staining and $\mathrm{H} \& \mathrm{E}$ grading were performed as previously described on tumors from 13.5-wk-old RT2 mice (Lopez and Hanahan 2002; Joyce et al. 2005). For each of these assays, data were collected using a double-blind protocol and independently assessed by two authors (V. Gocheva and J.A. Joyce). For comparisons of tumor vascularization, fields were randomly selected using a $20 \times$ objective lens from at least five tumors per mouse (typically 10-15) for three to nine mice per 13.5-wk-old group (see Fig. 2 legend for the exact numbers analyzed). The numbers of blood vessels per field were counted to calculate the MVD, subsequently de-coded, and statistical analysis performed. For BrdU and TUNEL quantitation, fields were randomly selected using a $40 \times$ objective lens from at least five tumors per mouse (typically 10-15) for three to 21 mice per 13.5-wk-old group (see the legends for Figs. 3, 4 for the exact numbers analyzed). The numbers of $\mathrm{BrdU}^{+}$or $\mathrm{TUNEL}^{+}$cells were counted as a percentage of the total cells per field. For tumor grading, paraffin or frozen tissue blocks were sectioned completely and tissue sections were stained with H\&E every 50 $\mu \mathrm{m}$. All tumors in the control and cathepsin-null 13.5-wk-old RT2 mice were graded in a double-blind manner into three types: encapsulated tumors (Tum), microinvasive carcinomas (IC1), or invasive carcinomas (IC2) (see the legend for Fig. 5 for the exact numbers analyzed). Invasion grading was independently confirmed by E-cadherin immunostaining on frozen sections, also graded double-blindly. All MVD, BrdU, and TUNEL analyses were performed on graded tumors, and there were no significant differences between the tumor subtypes, such that when reductions in MVD and cell proliferation or increases in apoptosis were evident, they were observed in each of the three tumor grades. The Wilcoxon $t$-test was used for calculation of $P$ values in the MVD, BrdU, and TUNEL analyses. A cumulative logit model (McCullagh 1980) with generalized estimating equations to correct for correlations within individual mice was used to compare the distribution of tumor types in the control RT2 group to the distribution of tumors in the other four $\mathrm{ca}$ thepsin knockout RT2 groups. Since the cathepsin +/- RT2 and cathepsin +/+ RT2 littermates were combined as the "controls" RT2 group, a stricter $P$ value of $<0.01$ was considered significant.

\section{TMA construction and cathepsin immunostaining}

A TMA was constructed from archival paraffin-embedded tissue from a series of 80 pancreatic endocrine tumors surgically resected from patients at MSKCC. Patient anonymity was ensured, and the study was performed in compliance with the Institutional Review Board. The pancreatic tumors used in the array included the following: 11 insulinomas (including one arising in a MEN1 patient), 63 nonfunctional PEN (with islet cell tumors representing the majority), and six metastases from PEN. Specimens of normal pancreas $(n=6)$ were also included in the TMA. Three 0.6- $\mathrm{mm}$ tissue cores were punched from representative areas of the donor block and embedded in a recipient block using an automated TMA machine. Five-micron tissue sections were cut from this TMA and from representative RT2 tissues, and staining for cathepsins B, C, L, and S was performed. All cathepsin antibodies were purchased from R\&D Systems and were used at concentrations of 1:500 to 1:5000 to immunostain tissues using standard protocols as previously described (Joyce et al. 2005). The cathepsin staining for each tissue specimen was scored independently in a double-blind manner by two authors (W. Zeng and J.A. Joyce) as negative (0) or positive [three levels: weak (1); moderate (2); strong (3)], based on stain intensity and percentage of cells that stained positive. In addition, the cell type(s) that stained for each cathepsin were noted as tumor, endothelial, or immune cell-positive, and this information was linked to the overall staining score. The percentage of staining intensity was graphed for each stage: normal pancreas, benign tumor, vascular invasive tumor, invasive tumor, metastatic primary tumor, and metastasis (to liver or lymph nodes). For each cathepsin, an overall test of differences among any of the groups (normal and all tumor stages) was performed. An exact version of Mantel Haenszel's test for trend (Mantel 1963) was performed to look for differences in staining in each tumor group compared with the normal controls. Since multiple comparisons were performed, a $P$ value of $<0.01$ was considered significant.

\section{Cathepsin activation and E-cadherin cleavage experiments}

Recombinant inactive cathepsins L, S, and B and active mouse cathepsin $\mathrm{C}$ were obtained from R\&D systems. Cathepsin L was activated at $10 \mathrm{ng} / \mathrm{\mu L}$ in $50 \mathrm{mM}$ MES, $5 \mathrm{mM}$ DTT (pH 6.0) for 15 min on ice. Cathepsin B was activated at $10 \mathrm{ng} / \mu \mathrm{L}$ in $25 \mathrm{mM}$ MES, $5 \mathrm{mM}$ DTT (pH 5.0) for $15 \mathrm{~min}$ at room temperature. Cathepsin $\mathrm{S}$ was activated at $10 \mathrm{ng} / \mathrm{\mu L}$ in $50 \mathrm{mM}$ sodium acetate, $5 \mathrm{mM}$ DTT, $0.25 \mathrm{M} \mathrm{NaCl}(\mathrm{pH} 4.5)$ for $1 \mathrm{~h}$ at $37^{\circ} \mathrm{C}$. Cathepsin $\mathrm{B}$ and $\mathrm{L}$ activation was confirmed using fluorogenic peptide substrate VII (R\&D systems), cathepsin S activation using fluorogenic peptide Substrate II (R\&D systems), and cathepsin C using G-R-AMC (MP Biomedicals). The reactions were carried out in $50 \mathrm{mM}$ sodium acetate, $5 \mathrm{mM}$ DTT $(\mathrm{pH} 5.5)$, and fluorescence was measured on a TECAN SpectraFluor Plus instrument (TECAN).

For the in vitro cleavage reaction, cathepsins were activated as described above and were incubated with equal amounts of recombinant human E-cadherin ( $\mathrm{R} \& \mathrm{D}$ systems) in reaction buffer $\left(50 \mathrm{mM}\right.$ sodium acetate, $0.04 \mathrm{mM} \mathrm{CaCl}_{2}, 5 \mathrm{mM}$ DTT at $\mathrm{pH} 5.5$ ) at $37^{\circ} \mathrm{C}$ for $15 \mathrm{~min}$. The amount of each cathepsin used was determined based on the specific activity of the enzyme. The reaction was stopped by addition of the cysteine protease inhibitor E-64 (15 $\mu \mathrm{M}$; Roche), followed by incubation for 15 min at room temperature. SDS sample buffer and reducing agent were added to each reaction, and the samples were boiled at $95^{\circ} \mathrm{C}$ for $5 \mathrm{~min}$. Aliquots of the reaction mixtures were separated on a $10 \%$ NuPAGE Novex Bis-Tris gel (Invitrogen) and subjected to Western blot analysis. The antibodies used were ECCD2, 1:1000 (epitope is in E-cadherin extracellular subdomain EC1) (Zymed); HECD-1, 1:1000 (E-cadherin extracellular subdomain EC2) (Zymed); and anti-human IgG-Fc, 1:10,000 (to detect IgG linker in recombinant E-cadherin) (Biodesign). All experiments were repeated independently at least three times.

\section{Acknowledgments}

We thank Erica Jackson, Maria Choi, Susan Cacacho, Ehud Drori, and Marina Vayner for excellent technical assistance, and Drs. Bedrick Gadea and Yufang Shao for technical advice. We gratefully acknowledge Drs. Harold Chapman (UCSF) and Christine Pham (Washington University) for providing cathep$\sin S$ and cathepsin $C$ knockout mice, respectively. We thank Elyn Reidel (MSKCC Biostatistics Department) for advice and assistance with statistical analyses. We thank Drs. Joan Massague, Pier Paolo Pandolfi, and Harold Varmus for critical reading of the manuscript. The work was supported by the Leukemia and Lymphoma Society (to J.A.J.), the Sidney Kimmel Foun- 
dation (to J.A.J.), NCI grant PO1 CA72006 A2 (to D.H.), and an American Cancer Society Professorship (to D.H.).

\section{Note added in proof}

An independent study in press describes similar effects of $c a$ thepsin $S$ mutants on RIP1-Tag2 angiogenesis (Wang et al. 2006).

\section{References}

Balaji, K.N., Schaschke, N., Machleidt, W., Catalfamo, M., and Henkart, P.A. 2002. Surface cathepsin B protects cytotoxic lymphocytes from self-destruction after degranulation. $J$. Exp. Med. 196: 493-503.

Beavon, I.R. 2000. The E-cadherin-catenin complex in tumour metastasis: Structure, function and regulation. Eur. J. Cancer 36 (13 Spec No): 1607-1620.

Bergers, G., Song, S., Meyer-Morse, N., Bergsland, E., and Hanahan, D. 2003. Benefits of targeting both pericytes and endothelial cells in the tumor vasculature with kinase inhibitors. J. Clin. Invest. 111: 1287-1295.

Camp, R.L., Charette, L.A., and Rimm, D.L. 2000. Validation of tissue microarray technology in breast carcinoma. Lab. Invest. 80: 1943-1949.

Cavallaro, U. and Christofori, G. 2004. Cell adhesion and signalling by cadherins and Ig-CAMs in cancer. Nat. Rev. Cancer 4: 118-132.

Cupisti, K., Hoppner, W., Dotzenrath, C., Simon, D., Berndt, I., Roher, H.D., and Goretzki, P.E. 2000. Lack of MEN1 gene mutations in 27 sporadic insulinomas. Eur. J. Clin. Invest. 30: 325-329.

Felbor, U., Kessler, B., Mothes, W., Goebel, H.H., Ploegh, H.L., Bronson, R.T., and Olsen, B.R. 2002. Neuronal loss and brain atrophy in mice lacking cathepsins B and L. Proc. Natl. Acad. Sci. 99: 7883-7888.

Folkman, J., Watson, K., Ingber, D., and Hanahan, D. 1989. Induction of angiogenesis during the transition from hyperplasia to neoplasia. Nature 339: 58-61.

Goulet, B., Baruch, A., Moon, N.S., Poirier, M., Sansregret, L.L., Erickson, A., Bogyo, M., and Nepveu, A. 2004. A cathepsin L isoform that is devoid of a signal peptide localizes to the nucleus in $\mathrm{S}$ phase and processes the $\mathrm{CDP} / \mathrm{Cux}$ transcription factor. Mol. Cell 14: 207-219.

Guicciardi, M.E., Miyoshi, H., Bronk, S.F., and Gores, G.J. 2001. Cathepsin B knockout mice are resistant to tumor necrosis factor- $\alpha$-mediated hepatocyte apoptosis and liver injury: Implications for therapeutic applications. Am. J. Pathol. 159: 2045-2054.

Halangk, W., Lerch, M.M., Brandt-Nedelev, B., Roth, W., Ruthenbuerger, M., Reinheckel, T., Domschke, W., Lippert, H., Peters, C., and Deussing, J. 2000. Role of cathepsin B in intracellular trypsinogen activation and the onset of acute pancreatitis. J. Clin. Invest. 106: 773-781.

Hanahan, D. 1985. Heritable formation of pancreatic $\beta$-cell tumours in transgenic mice expressing recombinant insulin/ simian virus 40 oncogenes. Nature 315: 115-122.

Hochwald, S.N., Zee, S., Conlon, K.C., Colleoni, R., Louie, O., Brennan, M.F., and Klimstra, D.S. 2002. Prognostic factors in pancreatic endocrine neoplasms: An analysis of 136 cases with a proposal for low-grade and intermediate-grade groups. J. Clin. Oncol. 20: 2633-2642.

Inoue, M., Hager, J.H., Ferrara, N., Gerber, H.P., and Hanahan, D. 2002. VEGF-A has a critical, nonredundant role in angiogenic switching and pancreatic $\beta$ cell carcinogenesis. Cancer
Cell 1: 193-202.

Jedeszko, C. and Sloane, B.F. 2004. Cysteine cathepsins in human cancer. Biol. Chem. 385: 1017-1027.

Jonkers, Y.M., Claessen, S.M., Perren, A., Schmid, S., Komminoth, P., Verhofstad, A.A., Hofland, L.J., de Krijger, R.R., Slootweg, P.J., Ramaekers, F.C., et al. 2005. Chromosomal instability predicts metastatic disease in patients with insulinomas. Endocr. Relat. Cancer 12: 435-447.

Joyce, J.A. and Hanahan, D. 2004. Multiple roles for cysteine cathepsins in cancer. Cell Cycle 3: 1516-1519.

Joyce, J.A., Baruch, A., Chehade, K., Meyer-Morse, N., Giraudo, E., Tsai, F.Y., Greenbaum, D.C., Hager, J.H., Bogyo, M., and Hanahan, D. 2004. Cathepsin cysteine proteases are effectors of invasive growth and angiogenesis during multistage tumorigenesis. Cancer Cell 5: 443-453.

Joyce, J.A., Freeman, C., Meyer-Morse, N., Parish, C.R., and Hanahan, D. 2005. A functional heparan sulfate mimetic implicates both heparanase and heparan sulfate in tumor angiogenesis and invasion in a mouse model of multistage cancer. Oncogene 24: 4037-4051.

Kerbel, R. and Folkman, J. 2002. Clinical translation of angiogenesis inhibitors. Nat. Rev. Cancer 2: 727-739.

Lochter, A., Galosy, S., Muschler, J., Freedman, N., Werb, Z., and Bissell, M.J. 1997. Matrix metalloproteinase stromelysin-1 triggers a cascade of molecular alterations that leads to stable epithelial-to-mesenchymal conversion and a premalignant phenotype in mammary epithelial cells. J. Cell Biol. 139: $1861-1872$.

Lopez, T. and Hanahan, D. 2002. Elevated levels of IGF-1 receptor convey invasive and metastatic capability in a mouse model of pancreatic islet tumorigenesis. Cancer Cell 1: 339353.

Mai, J., Finley Jr., R.L., Waisman, D.M., and Sloane, B.F. 2000. Human procathepsin B interacts with the annexin II tetramer on the surface of tumor cells. J. Biol. Chem. 275: 12806-12812.

Mantel, N. 1963. Chi-square tests with one degree of freedom: Extensions of the Mantel-Haenszel procedure. J. Am. Stat. Assoc. 58: 690-700.

Maretzky, T., Reiss, K., Ludwig, A., Buchholz, J., Scholz, F., Proksch, E., de Strooper, B., Hartmann, D., and Saftig, P. 2005. ADAM10 mediates E-cadherin shedding and regulates epithelial cell-cell adhesion, migration, and $\beta$-catenin translocation. Proc. Nat1. Acad. Sci. 102: 9182-9187.

McCullagh, P. 1980. Regression models for ordinal data. J. Roy. Stat. Soc. B 42: 109-142.

Mort, J.S., Recklies, A.D., and Poole, A.R. 1985. Release of cathepsin B precursors from human and murine tumours. Prog. Clin. Biol. Res. 180: 243-245.

Noe, V., Chastre, E., Bruyneel, E., Gespach, C., and Mareel, M. 1999. Extracellular regulation of cancer invasion: The E-cadherin-catenin and other pathways. Biochem. Soc. Symp. 65: 43-62.

Noe, V., Fingleton, B., Jacobs, K., Crawford, H.C., Vermeulen, S., Steelant, W., Bruyneel, E., Matrisian, L.M., and Mareel, M. 2001. Release of an invasion promoter E-cadherin fragment by matrilysin and stromelysin-1. J. Cell Sci. 114: 111118.

Perl, A.K., Wilgenbus, P., Dahl, U., Semb, H., and Christofori, G. 1998. A causal role for E-cadherin in the transition from adenoma to carcinoma. Nature 392: 190-193.

Pham, C.T. and Ley, T.J. 1999. Dipeptidyl peptidase I is required for the processing and activation of granzymes A and B in vivo. Proc. Natl. Acad. Sci. 96: 8627-8632.

Rao, J.S. 2003. Molecular mechanisms of glioma invasiveness: The role of proteases. Nat. Rev. Cancer 3: 489-501. 
Reinheckel, T., Deussing, J., Roth, W., and Peters, C. 2001. Towards specific functions of lysosomal cysteine peptidases: Phenotypes of mice deficient for cathepsin B or cathepsin L. Biol. Chem. 382: 735-741.

Roth, W., Deussing, J., Botchkarev, V.A., Pauly-Evers, M., Saftig, P., Hafner, A., Schmidt, P., Schmahl, W., Scherer, J., Anton-Lamprecht, I., et al. 2000. Cathepsin L deficiency as molecular defect of furless: Hyperproliferation of keratinocytes and perturbation of hair follicle cycling. FASEB J. 14: 2075-2086.

Ryniers, F., Stove, C., Goethals, M., Brackenier, L., Noe, V., Bracke, M., Vandekerckhove, J., Mareel, M., and Bruyneel, E. 2002. Plasmin produces an E-cadherin fragment that stimulates cancer cell invasion. Biol. Chem. 383: 159-165.

Saftig, P., Hunziker, E., Wehmeyer, O., Jones, S., Boyde, A., Rommerskirch, W., Moritz, J.D., Schu, P., and von Figura, K. 1998. Impaired osteoclastic bone resorption leads to osteopetrosis in cathepsin-K-deficient mice. Proc. Natl. Acad. Sci. 95: 13453-13458.

Shan, L., Nakamura, Y., Nakamura, M., Yokoi, T., Tsujimoto, M., Arima, R., Kameya, T., and Kakudo, K. 1998. Somatic mutations of multiple endocrine neoplasia type 1 gene in the sporadic endocrine tumors. Lab. Invest. 78: 471-475.

Shi, G.P., Villadangos, J.A., Dranoff, G., Small, C., Gu, L., Haley, K.J., Riese, R., Ploegh, H.L., and Chapman, H.A. 1999. Cathepsin $\mathrm{S}$ required for normal MHC class II peptide loading and germinal center development. Immunity 10: 197-206.

Simon, R. and Sauter, G. 2003. Tissue microarray (TMA) applications: Implications for molecular medicine. Expert Rev. Mol. Med. 2003: 1-12.

Stypmann, J., Glaser, K., Roth, W., Tobin, D.J., Petermann, I., Matthias, R., Monnig, G., Haverkamp, W., Breithardt, G., Schmahl, W., et al. 2002. Dilated cardiomyopathy in mice deficient for the lysosomal cysteine peptidase cathepsin L. Proc. Natl. Acad. Sci. 99: 6234-6239.

Turk, V., Turk, B., and Turk, D. 2001. Lysosomal cysteine proteases: Facts and opportunities. EMBO T. 20: 4629-4633.

Turk, B., Stoka, V., Rozman-Pungercar, J., Cirman, T., DrogaMazovec, G., Oresic, K., and Turk, V. 2002. Apoptotic pathways: Involvement of lysosomal proteases. Biol. Chem. 383: 1035-1044.

Turk, V., Turk, B., Guncar, G., Turk, D., and Kos, J. 2002. Lysosomal cathepsins: Structure, role in antigen processing and presentation, and cancer. Adv. Enzyme Regul. 42: 285-303.

Viola, K.V. and Sosa, J.A. 2005. Current advances in the diagnosis and treatment of pancreatic endocrine tumors. Curr. Opin. Oncol. 17: 24-27.

Vleminckx, K., Vakaet Jr., L., Mareel, M., Fiers, W., and van Roy, F. 1991. Genetic manipulation of E-cadherin expression by epithelial tumor cells reveals an invasion suppressor role. Cell 66: 107-119.

Wang, B., Sun, J., Kitamoto, S., Yang, M., Grubb, A., Chapman, H.A., Kalluri, R., and Shi, G.P. 2006. Cathepsin S controls angiogenesis and tumor growth via matrix-derived angiogenic factors. J. Biol. Chem. (in press).

Yasothornsrikul, S., Greenbaum, D., Medzihradszky, K.F., Toneff, T., Bundey, R., Miller, R., Schilling, B., Petermann, I., Dehnert, J., Logvinova, A., et al. 2003. Cathepsin L in secretory vesicles functions as a prohormone-processing enzyme for production of the enkephalin peptide neurotransmitter. Proc. Nat1. Acad. Sci. 100: 9590-9595.

Zhuang, Z., Vortmeyer, A.O., Pack, S., Huang, S., Pham, T.A., Wang, C., Park, W.S., Agarwal, S.K., Debelenko, L.V., Kester, M., et al. 1997. Somatic mutations of the MEN1 tumor suppressor gene in sporadic gastrinomas and insulinomas. Cancer Res. 57: 4682-4686. 


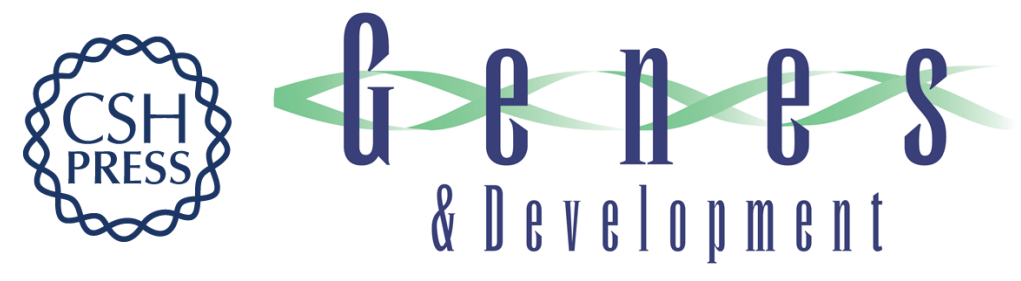

\section{Distinct roles for cysteine cathepsin genes in multistage tumorigenesis}

Vasilena Gocheva, Wei Zeng, Danxia Ke, et al.

Genes Dev. 2006, 20:

Access the most recent version at doi:10.1101/gad.1407406

\section{Supplemental http://genesdev.cshlp.org/content/suppl/2006/02/15/gad.1407406.DC1 Material}

References This article cites 47 articles, 14 of which can be accessed free at: http://genesdev.cshlp.org/content/20/5/543.full.html\#ref-list-1

\section{License}

Email Alerting

Service

Receive free email alerts when new articles cite this article - sign up in the box at the top right corner of the article or click here.

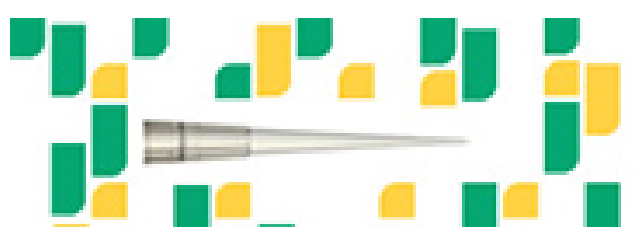

Focused on your science. 